Article

\title{
Three-Dimensional Hierarchical Porous Structure of PPy/Porous-Graphene to Encapsulate Polysulfides for Lithium/Sulfur Batteries
}

\author{
Yongguang Zhang ${ }^{1}$, Zhumabay Bakenov ${ }^{2}$ (D), Taizhe Tan ${ }^{1, *}$ and Jin Huang ${ }^{1, *}$ \\ 1 School of Materials and Energy, Synergy Innovation Institute of GDUT (Heyuan), Guangdong University of \\ Technology, Guangzhou 510006, China; ygzhang126@126.com \\ 2 Institute of Batteries LLC, National Laboratory Astana, School of Engineering, Nazarbayev University, \\ 53 Kabanbay Batyr Avenue, Astana 010000, Kazakhstan; zbakenov@nu.edu.kz \\ * Correspondence: tztansii18@163.com (T.T.); huangjiner@126.com (J.H.)
}

Received: 3 July 2018; Accepted: 3 August 2018; Published: 9 August 2018

\begin{abstract}
Herein, we demonstrate the fabrication of a three-dimensional (3D) polypyrrole-coatedporous graphene (PPy/PG) composite through in-situ polymerization of pyrrole monomer on PG surface. The PPy/PG displays a 3D hierarchical porous structure and the resulting PPy/PG hybrid serves as a conductive trap to lithium polysulfides enhancing the electrochemical performances. Owing to the superior conductivity and peculiar structure, a high initial discharge capacity of $1020 \mathrm{mAh} \mathrm{g}^{-1}$ and the reversible capacity of $802 \mathrm{mAh} \mathrm{g}^{-1}$ over 200 cycles are obtained for the $\mathrm{S} / \mathrm{PPy} / \mathrm{PG}$ cathode at $0.1 \mathrm{C}$, remaining the remarkable cyclic stability. In addition, the S/PPy/PG cathodes demonstrate an excellent rate performance exhibiting $477 \mathrm{mAh} \mathrm{g}^{-1}$ at $2 \mathrm{C}$.
\end{abstract}

Keywords: lithium/sulfur battery; hierarchical 3D porous structure; sulfur/polypyrrole/porous graphene composite

\section{Introduction}

Recently, lithium-ion batteries (LIBs) are being widely used in portable electronic devices and considered for future hybrid electric vehicles due to their high energy density and excellent cyclic performance. However, traditional LIBs with transition metal oxides cathodes and graphite-based anodes cannot meet the demand of the market due to the limited capacity of electrode materials for LIBs. Therefore, a considerable research effort has been focused on developing novel electrode materials with high theoretical specific capacity that can maximize the energy density of LIBs [1,2]. Furthermore, lithium/sulfur (Li/S) batteries exhibit significant advantages, such as the natural abundance and eco-friendly nature of sulfur, and high theoretical specific capacity of $1672 \mathrm{mAh} \mathrm{g}^{-1}$. The energy density of $2600 \mathrm{Wh} \mathrm{kg}^{-1}$ for Li/S batteries is five times larger than the traditional LIBs [3,4].

Despite these advantages, a number of challenges hinder the successful realization of $\mathrm{Li} / \mathrm{S}$ batteries. Firstly, the electrically insulated sulfur and the deposition of final discharge product $\mathrm{Li}_{2} \mathrm{~S}$ result in inefficient cathode material utilization and poor rate capability. Secondly, the high solubility and the shuttle effect of polysulfide intermediates lead to an irreversible capacity loss during charge/discharge cycling. Thirdly, the volumetric changes of the sulfur cathode during the charge/discharge process disrupt the integrity of composite electrode and result in loss of electrical contact [5]. These issues limit the practical utilization of sulfur as an alternative cathode material. Particularly, the volumetric changes, associated with sulfur, cause the shuttle effect and lead to the poor cyclic performance of $\mathrm{Li} / \mathrm{S}$ batteries [6-8].

In order to alleviate the aforementioned issues, various strategies have been proposed. The physical or chemical encapsulation of sulfur into a porous and conductive material is a widely 
employed approach to circumvent the volumetric changes and enhance the electrical conductivity of composite electrode [9]. Graphene is considered as an ideal sulfur host due to its chemical stability, large surface area, superior electrical conductivity and desirable mechanical properties [10]. Various research groups have shown promising results of sulfur/graphene composite cathodes for lithium/sulfur, however, the cyclic stability is not up to the mark yet. The main problem with graphene/sulfur composites lies with the weak interactions related to physical absorption. Hence, hybrid host structures, such as carbon/polymer composites [11] and carbon/metal oxide composites [12], are designed to enhance the physical interactions between sulfur and host material.

Recently, conducting polymers, such as polypyrrole (PPy), polyacrylonitrile and polythiophene, have garnered significant research attention due to their excellent electrochemical stability and ability to form favorable composite morphologies [13-15]. Moreover, owing to the simple synthesis process and the high absorption ability, the PPy is considered as a promising matrix to host sulfur for cathode applications [16].

Herein, we have successfully developed a facile and efficient template-assisted route to synthesize a novel three-dimensional (3D) hierarchical sulfur/polypyrrole/porous graphene (S/PPy/PG) composite, which deliver the excellent electrochemical performances as cathode for Li/S batteries. The study provides a mechanistic insight and opens up avenues for further research in Li/S batteries.

\section{Materials and Methods}

\subsection{Material Synthesis}

Graphene was obtained by the modified Hummers method [17]. Porous graphene (PG) was synthesized via a simple hydrothermal method and template etching process, which used commercial silica particles (diameter of about $300 \mathrm{~nm}$ ) as a hard template. To fabricate PG, $0.5 \mathrm{~g}$ of silica particles was immersed in $2.0 \mathrm{~g}$ of a homogeneous ethanol solution containing $0.5 \mathrm{~g}$ of resol and $0.5 \mathrm{~g}$ of triblock copolymer $\mathrm{EO}_{20} \mathrm{PO}_{70} \mathrm{EO}_{20}$ (P123) for $1 \mathrm{~h}$. The impregnated composites were removed from the solution and kept at room temperature for $6 \mathrm{~h}$, followed by heating at $100{ }^{\circ} \mathrm{C}$ for $24 \mathrm{~h}$. The samples were then calcined in $\mathrm{N}_{2}$ at $350{ }^{\circ} \mathrm{C}$ for $2 \mathrm{~h}$ at a heating rate of $1^{\circ} \mathrm{C} \mathrm{min}^{-1}$ to remove the soft template, and heated further to $900{ }^{\circ} \mathrm{C}$ at a rate of $5^{\circ} \mathrm{C} \mathrm{min}^{-1}$, which was followed by a $2 \mathrm{~h}$ soaking for further carbonation. Finally, PG was obtained after the silica particles were removed by washing with HF solution (5 wt. \%, $24 \mathrm{~h}$ ). With $\mathrm{FeCl}_{3}$ as an oxidant, the polypyrrole was prepared by using the chemical oxidation method. The method by in-situ polymerization of pyrrole in the presence of porous graphene can be used to prepare the polypyrrole-coated porous graphene (PPy/PG) composite [18]. Figure 1 illustrates the synthesis processs of S/PPy/PG composite schematically.

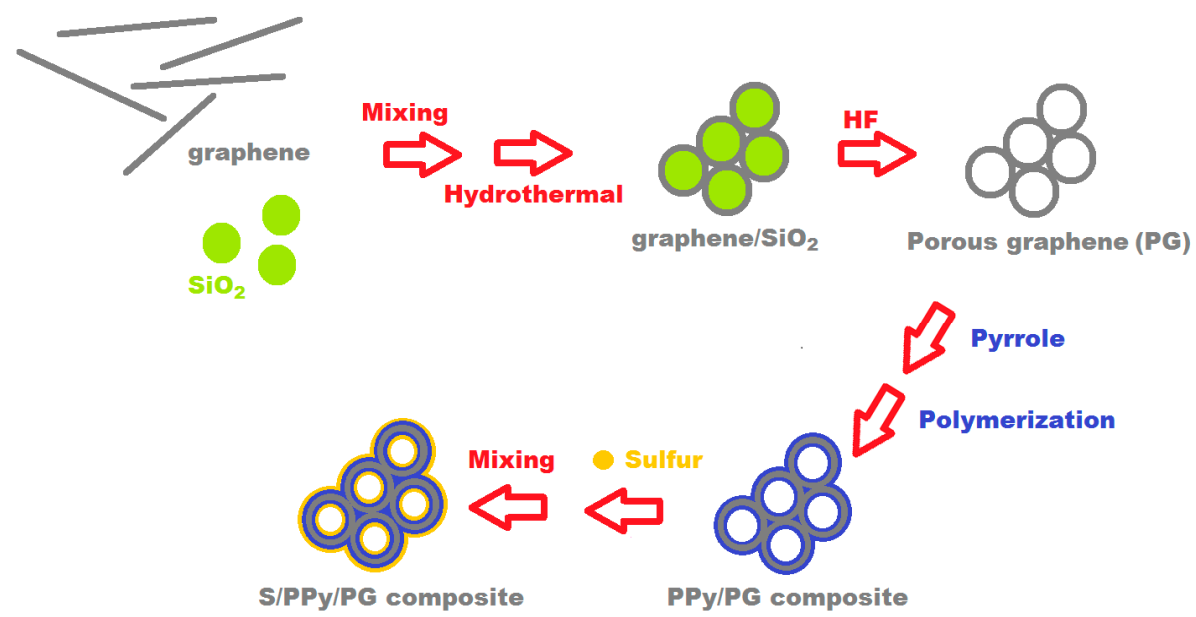

Figure 1. Schematic illustration of S/PPy/PG composite fabrication process. 
In a typical reaction, $0.1 \mathrm{~g}$ PG was added into a $45 \mathrm{~mL}$ mixture with methanol and acetonitrile (1:1 vol) for sonicating for $3 \mathrm{~h}$. After adding $0.3 \mathrm{~g}$ pyrrole, the mixture was stirred for $1 \mathrm{~h}$. Subsequently, we have added $20 \mathrm{~mL}$ of $0.5 \mathrm{~mol} \mathrm{~L}^{-1} \mathrm{FeCl}_{3}$ aqueous solution and the solution sonicated for $3 \mathrm{~h}$. The PPy/PG was obtained by centrifuging at $3000 \mathrm{rpm}$ for $0.5 \mathrm{~h}$. The product was cleaned with deionized water (DI) water and methanol, followed by vacuum drying at $80^{\circ} \mathrm{C}$ for $24 \mathrm{~h}$.

To obtain S/PPy/PG composites, $0.3 \mathrm{~g}$ PPy/PG was added into $6 \mathrm{~g}$ nano-sulfur aqueous suspension (US Nanomaterials, $10 \mathrm{wt}$. \%) in agate milling bowl (50 mL) and mixed well using ball-milling at $800 \mathrm{rpm}$ for $5 \mathrm{~h}$. The ball-milling was performed in a planetary ball mill (QM-3SP04, Nanjing, China) under ambient conditions. Then, the ball-milled suspension was dried at $75{ }^{\circ} \mathrm{C}$ for $24 \mathrm{~h}$ to remove the residual solvent. Finally, the obtained mixture was heat-treated at $155^{\circ} \mathrm{C} \mathrm{for} 2 \mathrm{~h}$ under Ar flow to sulfur be loaded in the PPy/PG composites to form S/PPy/PG.

\subsection{Material Characterization}

The sample was investigated by using Fourier transform infrared spectroscopy (FTIR, TENSOR 27, Bruker Co., Billerica, MA, USA). The field-emission scanning electron microscopy (FE-SEM, S-4800, Hitachi Ltd., Tokyo, Japan) could be used to characterize surface morphology and chemical composition, equipped with an energy dispersive spectrometer (EDS). The transmission electron microscopy (TEM, JEM-2100F, JEOL, Akishima-shi, Tokyo, Japan) could analysis the high-resolution surface structure. The crystalline phases were measured by X-ray diffraction (XRD) analysis (D8 Focus, Bruker, Karlsruhe, Germany). The X-ray photoelectron spectroscopy (XPS, K-Alpha, Thermo Scientific, Waltham, MA, USA) could analysis surface composition. The thermogravimetric analysis (TGA, SDT Q600, TA Instruments-Waters LLC, New Castle, DE, USA) was carried out to assess the weight percentage of components under $\mathrm{N}_{2}$ atmosphere in the range of $25-800{ }^{\circ} \mathrm{C}$.

\subsection{Electrochemical Characterization}

The electrochemical performances of the S/PPy/PG cathodes for Li/S batteries were carried out. The electrodes were obtained by mixing the S/PPy/PG composite ( $80 \mathrm{wt}$ \%), polyvinylidene fluoride (PVDF) binder (10 wt. \%) and Ketjen Black (10 wt. \%) via using 1-methyl-2-pyrrolidinone (NMP). The homogeneously slurry was pasted onto the carbon-coated aluminum foil and then dried at $60{ }^{\circ} \mathrm{C}$ for $12 \mathrm{~h}$. The sulfur loading of $\sim 2 \mathrm{mg} \mathrm{cm}^{-2}$ was achieved. The prepared electrode served as a cathode, the pure lithium metal served as the anode and the microporous polypropylene served as a separator. The galvanostatic charge-discharge testing was carried out to assess the Li-storage capacity and cyclic performance of the S/PPy/PG composite. The charge/discharge curves were recorded between $1.5 \mathrm{~V}$ and $3.0 \mathrm{~V}$ vs. $\mathrm{Li} / \mathrm{Li}^{+}$. The cyclic voltammetry $(\mathrm{CV})$ was measured with an electrochemical workstation (VersaSTAT 4, Princeton Applied Research, Oak Ridge, TN, USA) at scan rate of $0.1 \mathrm{mV} \mathrm{s}^{-1}$.

\section{Results and Discussion}

Figure 2a delivers the XRD patterns of PG sample has shown typical graphene peaks at $24^{\circ}$ and $43^{\circ}$, corresponding to the (002) and (100) planes, respectively [19]. After in-situ polymerization of pyrrole monomer on PG surface and carbonization process, the position of these peaks did not exhibit a significant change, which indicates that the PPy has been uniformly distributed on PG surface. After further sulfur loading, the XRD patterns of S/PPy/PG composite exhibited typical sulfur peaks, indicating that most of the sulfur has been diffused into the cavities of PPy/PG and homogeneously dispersed in fabricated composite [20].

The XPS analysis of S/PPy/PG composites was carried out to confirm the elemental composition and results are shown in Figure $2 b-d$. In high-resolution $C$ 1s XPS spectra (Figure 2b), the distinct peaks of $\mathrm{C}-\mathrm{C}, \mathrm{C}-\mathrm{S}, \mathrm{C}-\mathrm{N}, \mathrm{C}-\mathrm{O}$ and $\mathrm{C}=\mathrm{O}$ are shown. The $\mathrm{C}-\mathrm{C}$ peak at around $284.2 \mathrm{eV}$ corresponds to the carbon bond in PPy, and the $\mathrm{C}-\mathrm{C}$ peak located at $284.7 \mathrm{eV}$ confirms the presence of carbon bond in PPy and PG. In addition, the weak intensity ratio of $\mathrm{C}-\mathrm{O} / \mathrm{C}-\mathrm{C}$ peaks demonstrates the reduction effect in PG samples [21]. The high-resolution N 1s spectrum (Figure 2c) reveals the pyridinic-N (399.7 eV) 
and pyrrolic-N (400.4 eV), respectively [22]. In Figure 2d, the peaks at 164.1 and $165.3 \mathrm{eV}$ represent the S-O bonds, indicating a interaction between sulfur and PG in the S/PPy/PG composite. As a result, the nitrogen of PPy, which is coated on the PG surface, and the oxygen-containing functional groups of PG effectively riveted the sulfur onto the surface of S/PPy/PG. Owing to this beneficial phenomenon, the electrochemical performance of S/PPy/PG composite electrodes has been enhanced.
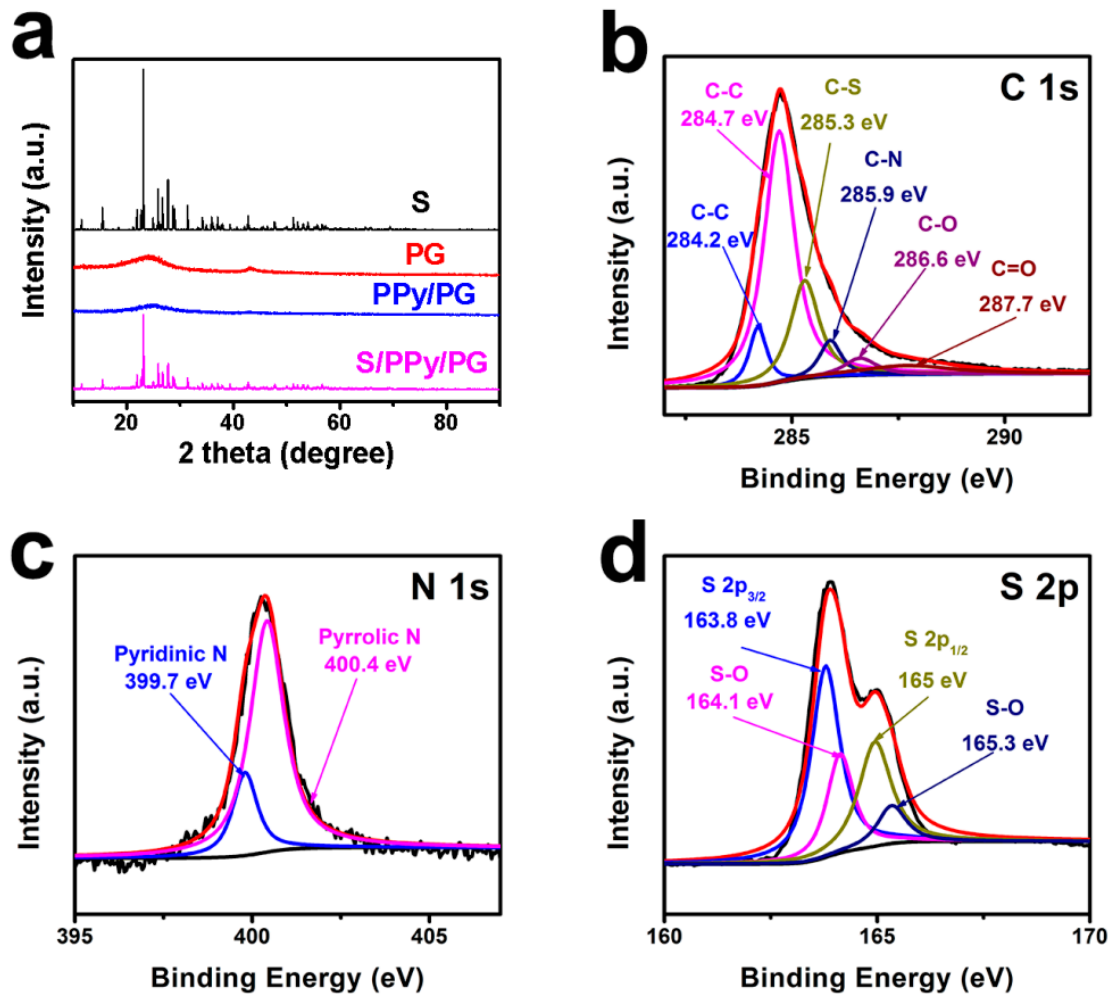

Figure 2. (a) XRD patterns of S, PG, PPy/PG and S/PPy/PG composite; high-resolution XPS spectra from core level of (b) C 1s, (c) N 1s and (d) S 2p from S/PPy/PG composite.

Figure 3 presents the FTIR spectra of PPy/PG and S/PPy/PG composites. It can be clearly observed that the characteristic bands of the hybrid composites are corresponding to the published literature. The absorption bands, corresponding to $\mathrm{O}-\mathrm{H}$ stretching at $3500 \mathrm{~cm}^{-1}$ and symmetric and asymmetric stretching of C-H at 2920 and $2901 \mathrm{~cm}^{-1}$, respectively, confirm the presence of PG in PPy/PG and S/PPy/PG composites. The presence of graphene was observed by C-C skeleton vibration of carbon ring, which has shown a characteristic band at $1562 \mathrm{~cm}^{-1}$. The characteristic pyrrole ring vibrations were observed at $1548 \mathrm{~cm}^{-1}$ and $1460 \mathrm{~cm}^{-1}$. The peaks located at $1092 \mathrm{~cm}^{-1}$ and $1308 \mathrm{~cm}^{-1}$ correspond to $=\mathrm{C}-\mathrm{H}$ in-plane vibrations and the peak at $1162 \mathrm{~cm}^{-1}$ refers to the characteristic C-N stretching vibrations [23]. In addition, PPy/PG and S/PPy/PG composites have shown that sulfur did not react with PPy and PG during the loading process. The decreased bands intensity in $\mathrm{S} / \mathrm{PPy} / \mathrm{PG}$ composite can be ascribed to the decrease in PPy content. These results confirm that the PPy/PG hybrid architectures have been successfully prepared via in-situ chemical polymerization.

As shown in Figure $4 a-c$, PG exhibits a 3D hierarchical porous structure, which processes a pore diameter of about $300 \mathrm{~nm}$. The adsorption of pyrrole monomers on PG surface resulted from $\pi-\pi$ interaction, hydrogen bonding and Van der Waals interactions, which served as an anchor for further polymerization. After sulfur loading, the morphology of PPy/PG did not show a significant change, indicating that a large amount of sulfur has been loaded between the pores of the PPy/PG and a smaller amount has been attached to the surface. The elemental mapping (Figure $4 \mathrm{~d}$ ) confirms the highly uniform dispersion of sulfur, PG and PPy in the S/PPy/PG composites. As shown in the TEM images (Figure 4e,f), the structure and morphology of PPy/PG composites remained same, which indicates 
that PPy has been formed and fixed on PG surface after polymerization. As sulfur is heavier than graphene and PPy, the darker region in TEM image can be ascribed to sulfur, as shown in Figure $4 \mathrm{~g}$. Due to the unique hybrid structure of a highly porous composite, which can provide a large interfacial area between electrode and electrolyte to buffer volumetric changes, the Li/S batteries with S/PPy/PG composite cathodes have exhibited a remarkable rate capacity and excellent cycling stability.

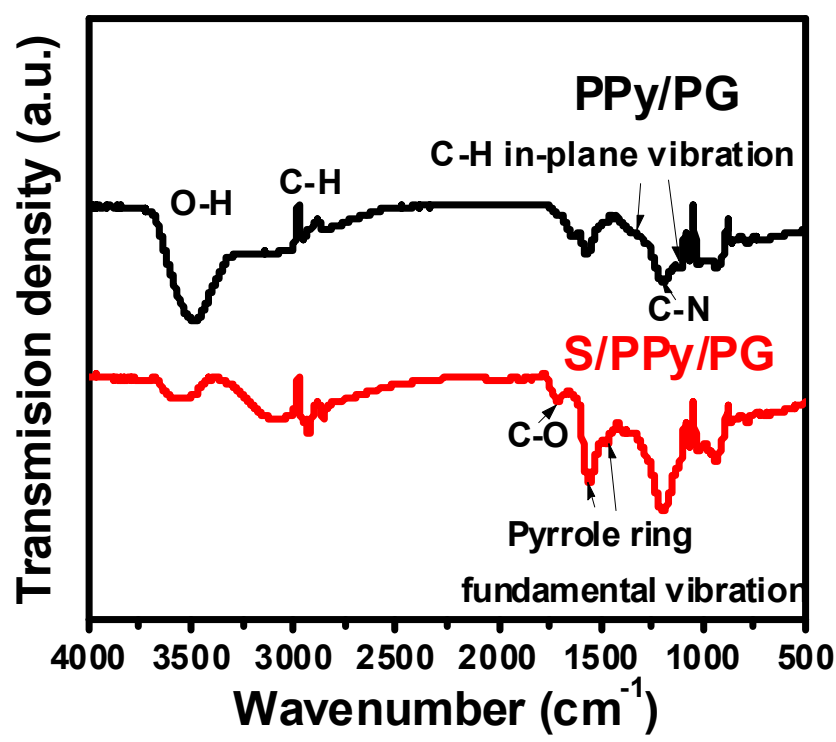

Figure 3. The FTIR spectra of PPy/PG and S/PPy/PG composites.
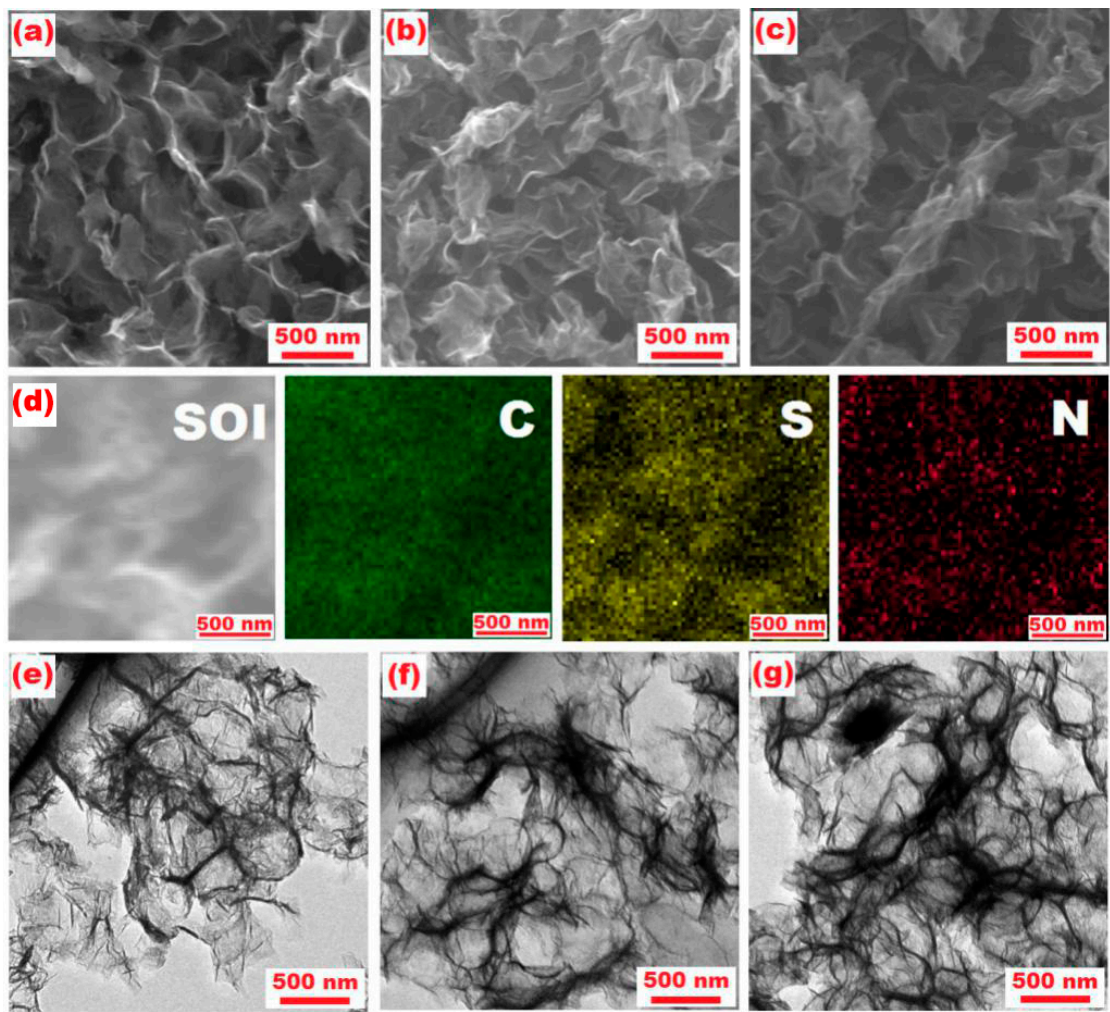

Figure 4. SEM images of (a) PG, (b) PPy/PG, and (c) S/PPy/PG; SEM image of (d) S/PPy/PG and corresponding elemental mapping of carbon (C), sulfur (S) and nitrogen (N); TEM images of (e) PG, (f) PPy/PG and (g) S/PPy/PG composite. 
The content of sulfur in the S/PPy/PG composite was estimated by TGA in Figure 5, which had a rapid weight loss during $25-300{ }^{\circ} \mathrm{C}$ with a remaining mass of $37.84 \%$, which can be attributed to the loss of $S$ and thermal decomposition of PPy. The weight loss of PPy was $7.66 \%$ in the range of 25-300 ${ }^{\circ} \mathrm{C}$. The sulfur content of S/PPy/PG composite $(\mathrm{X})$ was calculated from the given formula:

$$
62.16 \%=X \%+(100 \%-X \%) \times 7.66 \%
$$

The sulfur loading was found to be $59 \%$.

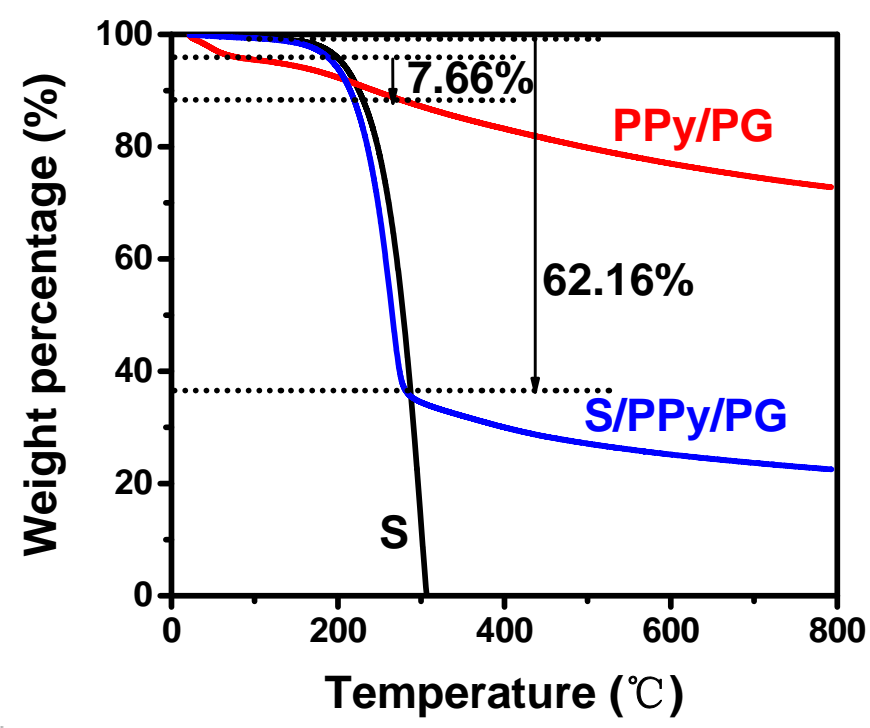

Figure 5. TGA curves of sulfur, PPy/PG and S/PPy/PG composite.

The initial three CV curves for the S/PPy/PG electrode are shown in Figure 6. During the cathodic sweep, two typical peaks are located at 2.25 and $2.0 \mathrm{~V}$, corresponding to the transformation of sulfur to polysulfides $\left(\mathrm{Li}_{2} \mathrm{~S}_{\mathrm{n}}, 4 \leq \mathrm{n} \leq 8\right)$ and finally to $\mathrm{Li}_{2} \mathrm{~S}_{2}$ and $\mathrm{Li}_{2} \mathrm{~S}$, respectively [24]. In the anodic scan, one major peak was observed at about $2.5 \mathrm{~V}$, revealing the oxidation of sulfides to sulfur [25]. We have not observed any peak shift or the emergence of new peaks during further cycling, suggesting excellent electrochemical stability due to the hybrid porous structure of electrode [26].

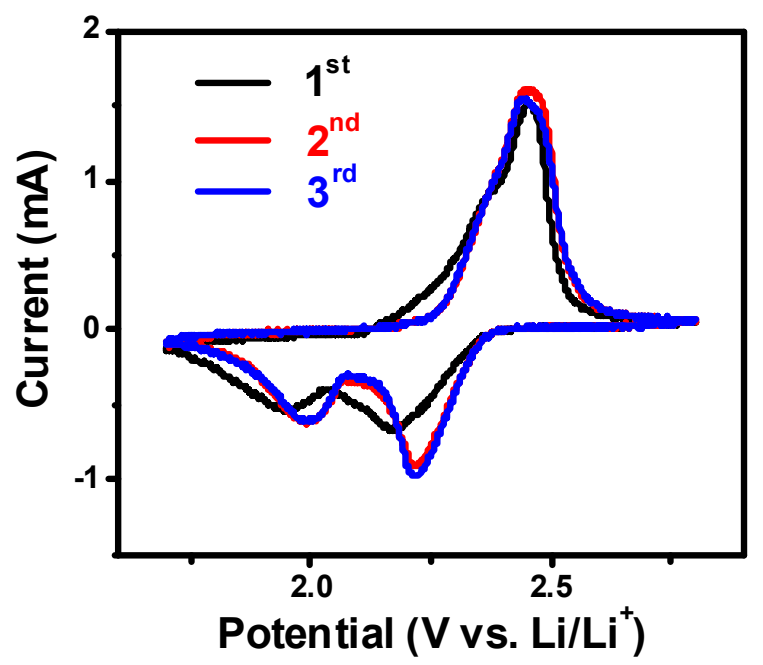

Figure 6. Initial three CV curves of S/PPy/PG composite electrode at a scan rate of $0.1 \mathrm{mV} \mathrm{s}^{-1}$. 
Figure 7 shows the galvanostatic charge-discharge curves of the S/PPy/PG composites at $0.1 \mathrm{C}$. Two reduction plateaus, consistent with CV curves, were observed in the discharge process. The voltage plateau at 2.3 and $2.0 \mathrm{~V}$ are corresponded to the formation of soluble polysulfides and reduction of soluble polysulfides to $\mathrm{Li}_{2} \mathrm{~S}_{2}$ or $\mathrm{Li}_{2} \mathrm{~S}$, respectively [27]. In addition, the second flat plateau suggests a uniform formation of $\mathrm{Li}_{2} \mathrm{~S}$ [28]. In the 50th, 100th, 150th and 200th cycles, the discharge process exhibits the similar voltage plateaus, which indicates the excellent stability of the fabricated composites.

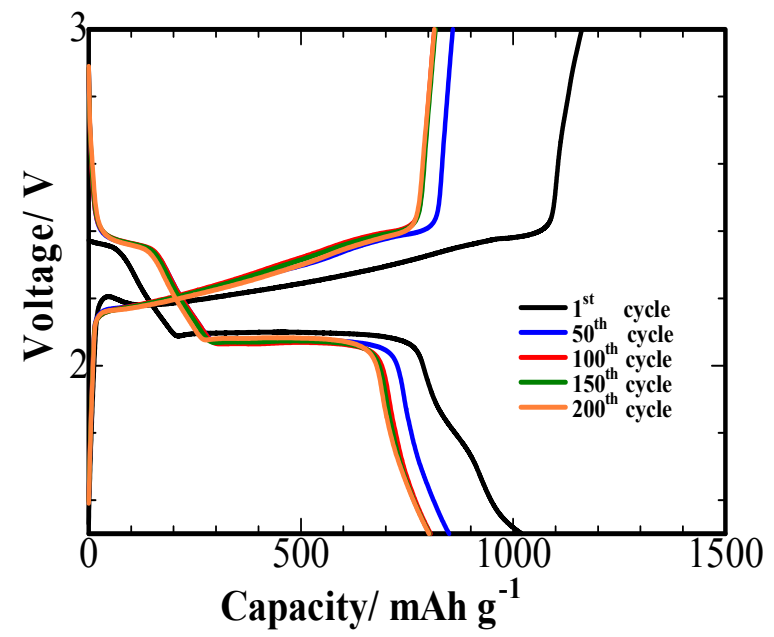

Figure 7. Charge-discharge profiles of S/PPy/PG composite electrode for the 1st, 50th, 100th, 150th and 200th cycles at $0.1 \mathrm{C}$.

Furthermore, the S/PPy / PG electrodes have demonstrated excellent cycling stability at $0.1 \mathrm{C}$, and rate performance. Figure 8 presents the cyclic stability of S/PPy/PG electrodes at $0.1 \mathrm{C}$. The initial specific discharge capacity of $1020 \mathrm{mAh} \mathrm{g}^{-1}$ and the capacity retention of $78.6 \%$ after 200 cycles are obtained for the S/PPy/PG composite, which corresponds to a low fade rate of $0.1 \%$ per cycle. In addition, the coulombic efficiency of S/PPy/PG electrode remained $\sim 100 \%$ during charge/discharge cycling, which indicates that the hybrid core-shell and 3D hierarchical porous structure of S/PPy/PG suppresses the shuttle effect.

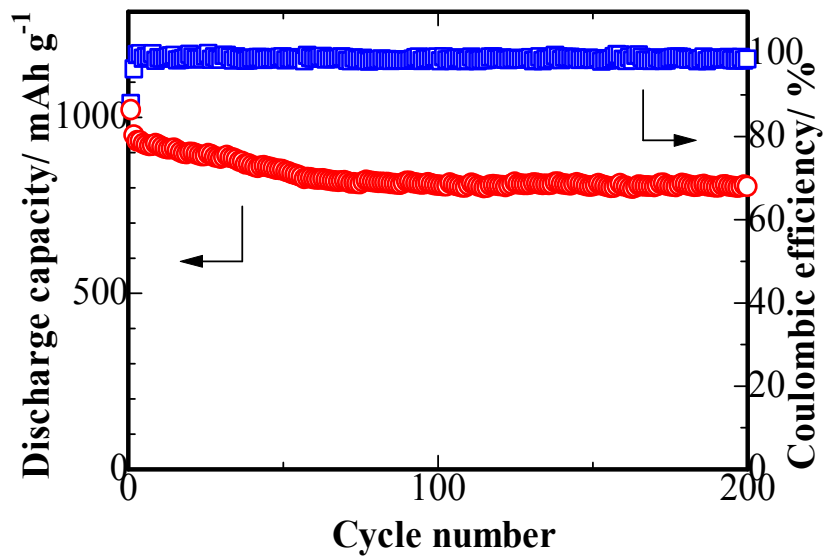

Figure 8. The cyclic performance of S/PPy/PG composite electrode at $0.1 \mathrm{C}$.

Figure 9 shows the first ten charge/discharge cycles were carried out at $0.1 \mathrm{C}$, followed by a stepwise increase towards the higher current densities. The S/PPy/PG composite electrode delivered the specific capacity of $927,805,661,566$ and $477 \mathrm{mAh} \mathrm{g}^{-1}$ at $0.1,0.2,0.5,1$ and $2 \mathrm{C}$, respectively. Once the current density was returned to the lower value of $0.1 \mathrm{C}$, the discharge capacity of $816 \mathrm{mAh} \mathrm{g}^{-1}$ 
is recovered, presenting the excellent rate performance. Owing to the hierarchical mesoporous and macroporous structure and enhanced conductivity of S/PPy/PG cathode, the higher capacity, excellent cyclic performance and superior rate capability were realized.
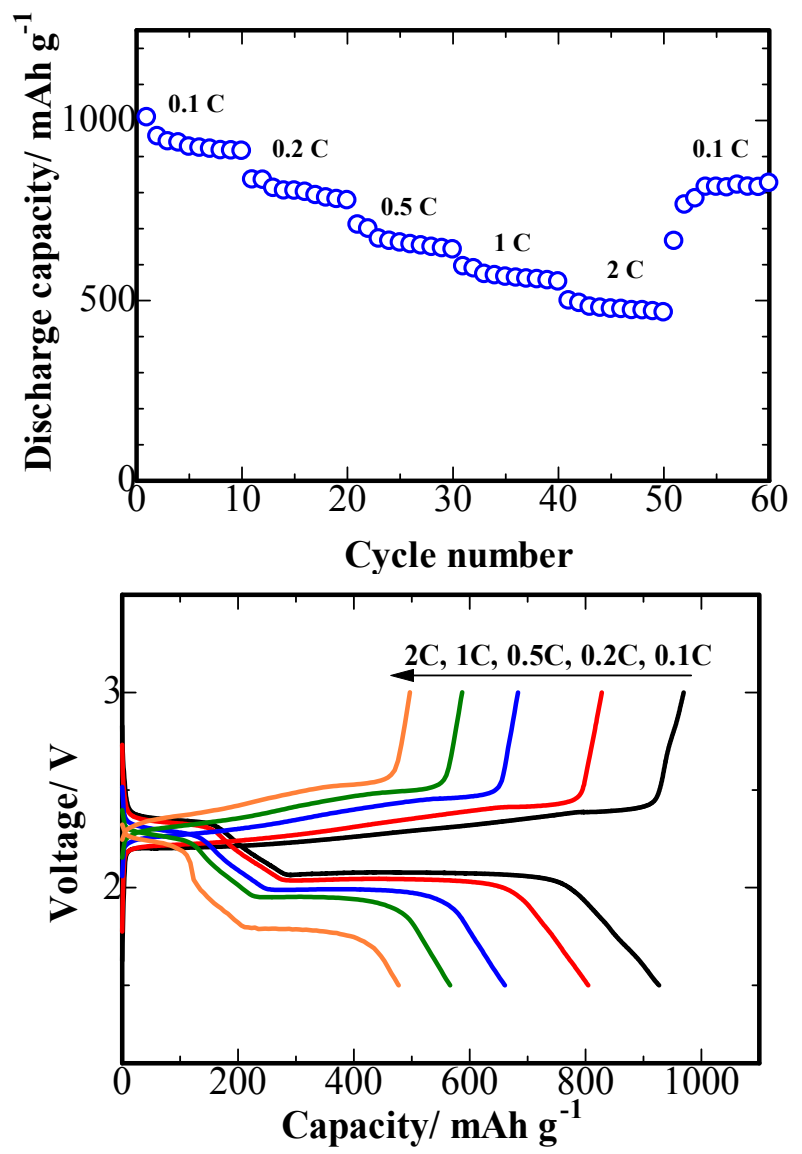

Figure 9. The rate performance of the S/PPy/PG composite electrode, measured by carrying out charge/discharge testing at various current rates.

\section{Conclusions}

In summary, we have successfully obtained sulfur impregnated polypyrrole-coated porous graphene (S/PPy/PG) composite, with a 3D hierarchical porous structure, which has demonstrated superior cycling stability and rate performance. The PG sample was synthesized by using template-assisted hydrothermal process and in-situ chemical polymerization of pyrrole monomer was carried out, which resulted in PPy-deposited PG surfaces. Furthermore, the S/PPy/PG composite cathode has shown an excellent cyclic stability, corresponding to a reversible capacity of $802 \mathrm{mAh} \mathrm{g}^{-1}$ after 200 cycles. The study provides a novel route to synthesize 3D hierarchical porous network structure and opens up avenues for further research in the area of next-generation Li/S batteries.

Author Contributions: Formal Analysis, Z.B., Y.Z. and J.H.; Investigation, Y.Z.; Writing-Original Draft Preparation, T.T. and Y.Z.; Writing-Review \& Editing, Z.B. and J.H.; Supervision, J.H.; Project Administration, T.T.; Funding Acquisition, Y.Z.

Funding: This research was funded by the China Postdoctoral Science Foundation (2018M630924); Program for the Outstanding Talents of Guangdong sailing plan, Human Resources and Social Security of Guangdong Province (201634007). Z.B. acknowledges the support from the targeted funding program BR05236524 by the Ministry of Education and Science of Kazakhstan.

Conflicts of Interest: The authors declare no conflict of interest. 


\section{References}

1. Odani, A.; Nimberger, A.; Markovsky, B.; Sominski, E.; Levi, E.; Kumar, V.G.; Motiei, M.; Gedanken, A.; Dan, P.; Aurbach, D. Development and testing of nanomaterials for rechargeable lithium batteries. J. Power Sources 2003, 119-121, 517-521. [CrossRef]

2. Li, H.P.; Sun, L.C.; Zhang, Y.G.; Tan, T.Z.; Wang, G.K.; Bakenov, Z. Enhanced cycle performance of Li/S battery with the reduced graphene oxide/activated carbon functional interlayer. J. Energy Chem. 2017, 26, 1276-1281. [CrossRef]

3. Kim, J.K. Hybrid gel polymer electrolyte for high-safety lithium-sulfur batteries. Mater. Lett. 2017, 187, 40-43. [CrossRef]

4. Xu, H.H.; Qie, L.; Manthiram, A. An integrally-designed, flexible polysulfide host for high-performance lithium-sulfur batteries with stabilized lithium-metal anode. Nano Energy 2016, 26, 224-232. [CrossRef]

5. Griebel, J.J.; Glass, R.S.; Char, K. Polymerizations with elemental sulfur: A novel route to high sulfur content polymers for sustainability, energy and defense. Prog. Polym. Sci. 2016, 58, 90-125. [CrossRef]

6. Choudhury, S.; Krüner, B.; Massuti-Balleter, P.; Tolosa, A.; Prehal, C.; Grobelsek, I.; Paris, O.; Borchardt, L.; Presser, V. Microporous novolac-derived carbon beads/sulfur hybrid cathode for lithium-sulfur batteries. J. Power Sources 2017, 357, 198-208. [CrossRef]

7. Zellmer, S.; Titscher, P.; Wienken, E.; Kwade, A.; Garnweitner, G. Fabrication of carbon-sulphur composites via a vibration mill process as cathode material for lithium sulphur batteries. Energy Storage Mater. 2017, 9, 70-77. [CrossRef]

8. Chiochan, P.; Phattharasupakun, N.; Wutthiprom, J.; Suksomboon, M.; Kaewruang, S.; Suktha, P.; Sawangphruk, M. Core-double shell sulfur@carbon black nanosphere@oxidized carbon nanosheet composites as the cathode materials for Li-S batteries. Electrochim. Acta 2017, 237, 78-86. [CrossRef]

9. Agrawal, M.; Choudhry, S.; Gruber, K.; Simon, F.; Fischer, D.; Albrecht, V.; Göbel, M.; Koller, S.; Stamm, M.; Ionov, L. Porous carbon materials for $\mathrm{Li}-\mathrm{S}$ batteries based on resorcinol-formaldehyde resin with inverse opal structure. J. Power Sources 2014, 261, 363-370. [CrossRef]

10. Yu, M.; Li, R.; Wu, M.; Shi, G. Graphene materials for lithium-sulfur batteries. Energy Storage Mater. 2015, 1, 51-73. [CrossRef]

11. Zhao, Y.; Zhang, Y.G.; Bakenov, Z.; Chen, P. Electrochemical performance of lithium gel polymer battery with nanostructured sulfur/carbon composite cathode. Solid State Ion. 2013, 234, 40-45. [CrossRef]

12. Rehman, S.; Tang, T.Y.; Ali, Z.; Huang, X.X.; Hou, Y.L. Integrated Design of $\mathrm{MnO}_{2} @$ Carbon Hollow Nanoboxes to Synergistically Encapsulate Polysulfides for Empowering Lithium Sulfur Batteries. Small 2017, 13, 363-370. [CrossRef] [PubMed]

13. Yin, F.X.; Liu, X.; Zhao, Y.; Zhang, Y.G.; Menbayeva, A.; Bakenov, Z.; Wang, X. Well-dispersed sulfur anchored on interconnected polypyrrole nanofiber network as high performance cathode for lithium-sulfur batteries. Solid State Sci. 2017, 66, 44-49. [CrossRef]

14. Sohn, H.; Gordin, M.L.; Regula, M.; Kim, D.H.; Song, J.; Wang, D. Porous spherical polyacrylonitrile-carbon nanocomposite with high loading of sulfur for lithium-sulfur batteries. J. Power Sources 2016, 302, 70-78. [CrossRef]

15. Erhardt, C.; Sörgel, S.; Meinhard, S.; Sörgel, T. Proof of concept for a novel, binder-free and conducting carbon-free sulfur battery cathode: Composite electroformation of copper foil with incorporated polythiophene wrapped sulfur particles. J. Power Sources 2015, 296, 70-77. [CrossRef]

16. Rao, J.; Xu, R.; Zhou, T.; Zhang, D.; Zhang, C. Rational design of self-supporting graphene-Polypyrrole/ sulfur-Graphene sandwich as structural paper electrode for lithium sulfur batteries. J. Alloys Compd. 2017, 728, 376-382. [CrossRef]

17. Chen, J.; Yao, B.; Li, C.; Shi, G. An improved Hummers method for eco-friendly synthesis of graphene oxide. Carbon 2013, 64, 225-229. [CrossRef]

18. Percec, S.; Howe, L.; Li, J.; Bagshaw, A.; Peacock, S.; Brill, D. Pyrrole polymerization on polyimide surfaces creates conductive nano-domains. Polymer 2013, 54, 5754-5761. [CrossRef]

19. Qian, W.; Gao, Q.; Zhang, H.; Tian, W.; Li, Z.; Tan, Y. Crosslinked Polypyrrole Grafted Reduced Graphene Oxide-Sulfur Nanocomposite Cathode for High Performance Li-S Battery. Electrochim. Acta 2017, 235, $32-41$. [CrossRef] 
20. Yang, C.; Zhang, L.; Hu, N.; Yang, Z.; Wei, H.; Zhang, Y. Reduced graphene oxide/polypyrrole nanotube papers for flexible all-solid-state supercapacitors with excellent rate capability and high energy density. J. Power Sources 2016, 302, 39-45. [CrossRef]

21. Han, P.; Yue, Y.; Liu, Z.; Xu, W.; Zhang, L.; Xu, H.; Dong, S.; Cui, G. Graphene oxide nanosheets/multi-walled carbon nanotubes hybrid as an excellent electrocatalytic material towards $\mathrm{VO}^{2+} / \mathrm{VO}_{2}{ }^{+}$redox couples for vanadium redox flow batteries. Energy Environ. Sci. 2011, 4, 4710-4717. [CrossRef]

22. Xu, L.; Yang, W.; Neoh, K.; Kang, E.; Fu, G. Dopamine-Induced Reduction and Functionalization of Graphene Oxide Nanosheets. Macromolecules 2010, 43, 8336-8339. [CrossRef]

23. Xue, K.; Zhou, S.; Shi, H.; Feng, X.; Xin, H.; Song, W. A novel amperometric glucose biosensor based on ternary gold nanoparticles/polypyrrole/reduced graphene oxide nanocomposite. Sens. Actuators B Chem. 2014, 203, 412-416. [CrossRef]

24. Li, X.; Lushington, A.; Liu, J.; Li, R.; Sun, X. Superior stable sulfur cathodes of Li-S batteries enabled by molecular layer deposition. Chem. Commun. 2014, 50, 9757-9760. [CrossRef] [PubMed]

25. Ding, B.; Yuan, C.; Shen, L.; Xu, G.; Nie, P.; Zhang, X. Encapsulating Sulfur into Hierarchically Ordered Porous Carbon as a High-Performance Cathode for Lithium-Sulfur Batteries. J. Mater. Chem. A 2013, 19, 1013-1019. [CrossRef] [PubMed]

26. Zhang, Y.G.; Zhao, Y.; Bakenov, Z.; Tuiyebayeva, M.; Konarov, A.; Chen, P. Synthesis of Hierarchical Porous Sulfur/Polypyrrole/Multiwalled Carbon Nanotube Composite Cathode for Lithium Batteries. Electrochim. Acta 2014, 143, 49-55. [CrossRef]

27. Yamin, H.; Gorenshtain, A.; Penciner, J.; Sternberg, Y.; Peled, E. Lithium Sulphur Battery Oxidation/ Reduction Mechanisms of Polysulphides in THF solution. J. Electrochem. Soc. 1988, 135, 1045-1048. [CrossRef]

28. Zhang, Y.G.; Zhao, Y.; Konarov, A.; Gosselink, D.; Soboleski, H.G.; Chen, P. A novel nano-sulfur/polypyrrole/ graphene nanocomposite cathode with a dual-layered structure for lithium rechargeable batteries. J. Power Sources 2013, 241, 517-521. [CrossRef]

(C) 2018 by the authors. Licensee MDPI, Basel, Switzerland. This article is an open access article distributed under the terms and conditions of the Creative Commons Attribution (CC BY) license (http://creativecommons.org/licenses/by/4.0/). 